\title{
Density and viscosity of magnesium sulphate in formamide + ethylene glycol mixed solvents
}

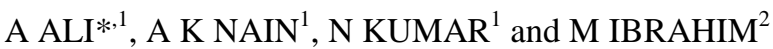 \\ ${ }^{1}$ Department of Chemistry and ${ }^{2}$ University Polytechnic, Jamia Millia Islamia \\ (Central University), New Delhi 110 025, India \\ e-mail: anwar.ch@jmi.ernet.in
}

MS received 15 March 2002; revised 4 July 2002

\begin{abstract}
Densities $(\rho)$ and viscosities $(\eta)$ of different strengths of magnesium sulphate $\left(\mathrm{MgSO}_{4}\right)$ in varying proportions of formamide (FA) + ethylene glycol as mixed solvents were measured at room temperature. The experimental values of $\rho$ and $\eta$ were used to calculate the values of the apparent molar volume, $\left(\phi_{v}\right)$, partial molar volume, $\left(\phi_{v}^{\circ}\right)$ at infinite dilution, $A$ - and $B$-coefficients of the Jones-Dole equation and free energies of activation of viscous flow, $\left(\Delta \mu_{1}^{0^{*}}\right)$ and $\left(\Delta \mu_{2}^{0^{*}}\right)$, per mole of solvent and solute respectively. The behaviour of these parameters suggests strong ion-solvent interactions in these systems and also that $\mathrm{MgSO}_{4}$ acts as structure-maker in FA + ethylene glycol mixed solvents.
\end{abstract}

Keywords. Magnesium sulphate; formamide-ethylene glycol mixture; activation energy of viscous flow.

\section{Introduction}

Studies on the behaviour of ions in mixed water + non-aqueous solvents have received a lot of attention in the recent past ${ }^{1-3}$. However, similar studies of electrolytes in nonaqueous binary solvents are scarce in the literature. Precise data on electrolytes in mixed solvents find applications in many industrial processes, as they provide a wide choice of solutions with appropriate properties. An attempt has been made to investigate the ionsolvent interactions of magnesium sulphate $\left(\mathrm{MgSO}_{4}\right)$ in formamide $(\mathrm{FA})$ and ethylene glycol mixtures. In the pure liquid, FA molecules are self-associated through intermolecular H-bonding, while those of ethylene glycol molecules are self-associated through inter- as well as intra-molecular hydrogen bonding ${ }^{4}$. It is found that the character of the molecular interaction considerably influences the solvation of ions. Thus, FA + ethylene glycol mixed solvents would be interesting media for the study of ionsolvent and solvent-solvent interactions of $\mathrm{MgSO}_{4}$.

In the present study, the density $(\rho)$ and viscosity $(\eta)$ of $\mathrm{MgSO}_{4}(0 \cdot 01,0 \cdot 05,0 \cdot 10,0 \cdot 15$ and 0.20 molar (M) solutions) in 20, 40 and $60 \%(v / v)$ FA + ethylene glycol mixtures have been measured at $298 \mathrm{~K}$. Experimental values of $\rho$ and $\eta$ were used to calculate the apparent molar volume $\left(\phi_{v}\right)$, limiting (infinite dilution) apparent molar volume (also called partial molar volume) $\left(\phi_{v}{ }^{\circ}\right), A$ - and $B$-coefficients of the Jones-Dole ${ }^{5}$ equation, and the free energies of activation of viscous flow $\left(\Delta \mu_{1}^{0^{*}}\right)$ and $\left(\Delta \mu_{2}^{0^{* *}}\right)$ per mole of

*For correspondence 
solvent and solute respectively, in all the three solvent mixtures. These parameters are the true representatives of the behaviour of ions in a given solution.

\section{Experimental}

Formamide used was the same as in our recent study ${ }^{6}$. Ethylene glycol (s.d. Fine, India) of AR grade was purified as described in the literature ${ }^{7} . \mathrm{MgSO}_{4} \cdot 7 \mathrm{H}_{2} \mathrm{O}$, also of same make and grade, was used without further purification, except for being dried over $\mathrm{P}_{2} \mathrm{O}_{5}$. The binary solvent mixtures of 20,40 and $60 \% \mathrm{FA}+$ ethylene glycol were prepared by volume. Mixtures of $0.01,0.05,0.10,0.15$ and $0.20 \mathrm{M}-\mathrm{MgSO}_{4}$ in all the three FA + ethylene glycol solvents were prepared in a dry atmosphere. All the solutions were kept tightly sealed to minimize absorption of atmospheric moisture and carbon dioxide. The weighings were done on an Afcoset ER-120A electronic balance with a precision of $\pm 0.1 \mathrm{mg}$. Densities of the mixed solvents and those of the solutions of $\mathrm{MgSO}_{4}$ in these solvents were measured with the help of a single-stem pycnometer of bulb capacity $8 \times 10^{-3} \mathrm{dm}^{3}$ with graduated marks on the stem. The neck of the stem could be closed with a well-fitting glass cap. The marks on the stem were calibrated using doubledistilled water. Viscosities were determined using an Ubbelhode type ${ }^{8}$ viscometer. The temperature of the solutions was maintained at $298 \pm 0.05 \mathrm{~K}$ in an electronically controlled thermostatic water bath. The accuracies in density and viscosity measurements were found to be $\pm 0.01 \mathrm{~kg} \mathrm{~m}^{-3}$ and $\pm 3 \times 10^{-6} \mathrm{Nm}^{-2}$ s respectively.

\section{Results and discussion}

Measured densities and viscosities of $0 \cdot 01,0 \cdot 05,0 \cdot 10,0 \cdot 15$ and $0 \cdot 20 \mathrm{M}-\mathrm{MgSO}_{4}$ in 20, 40 and $60 \%(v / v)$ FA + ethylene glycol solvents at $298 \mathrm{~K}$ are listed in table 1 . These experimental values of $\rho$ and $\eta$ were used to calculate the apparent molar volumes $\left(\phi_{v}\right)$ of $\mathrm{MgSO}_{4}$ in mixed solvents using the following relation,

$$
\phi_{v}=1000\left(\rho_{\mathrm{o}}-\rho\right) / C \rho_{\mathrm{o}}+M_{2} / \rho_{\mathrm{o}},
$$

where $\rho_{\mathrm{o}}$ and $\rho$ are the densities of the solvent and solution, respectively; $C$ is the molar concentration of electrolyte and $M_{2}$ is its molecular weight. The apparent molar volume $\left(\phi_{v}\right)$ was found to vary linearly with the square root of the concentration of the electrolyte. Hence, the partial molar volumes $\left(\phi_{v}{ }^{\circ}\right)\left(=\bar{V}^{0}\right)$ at infinite dilution were calculated by the method of least squares and fit to the plots of $\phi_{v}$ versus $C^{1 / 2}$ in accordance with Masson's empirical relation ${ }^{9}$,

$$
\phi_{v}=\phi_{v}{ }^{\circ}+S_{v} * C^{1 / 2} .
$$

The calculated values of $\phi_{v}{ }^{\circ}$ and $S_{v}{ }^{*}$, intercept and slope, of $\phi_{v}$ versus $C^{1 / 2}$ plots in 20, 40 and $60 \%(v / v)$ FA + ethylene glycol mixed solvents at $298 \mathrm{~K}$ are given in table $2 . S_{v}^{*}$ is a measure of ion-ion interaction and depends on charge, salt-type and nature of the solvent. Table 2 shows that all the values of $S_{v} *$ are large and negative indicating the presence of weak ion-ion interactions in the solution. Moreover, the values of $S_{v}{ }^{*}$ become less negative with increase in FA content in the system, suggesting increased ion-ion interaction in the FA-rich solvent. In fact, negative $S_{v}{ }^{*}$ values are often obtained in solvents of high dielectric constant ${ }^{10}$, as $\mathrm{FA}+$ ethylene glycol mixed solvents in the 
Table 1. Values of density $(\rho)$ and viscosity $(\eta)$ of $\mathrm{MgSO}_{4}+$ FA + ethylene glycol solutions as function of molar concentration $(C)$ of $\mathrm{MgSO}_{4}$ and volume (\%) of FA at $298 \mathrm{~K}$.

\begin{tabular}{lcc}
\hline$C$ (molar) & $\rho\left(\mathrm{kg} \mathrm{m}^{-3}\right)$ & $\eta\left(10^{-3} \mathrm{Nm}^{-2} \mathrm{~s}\right)$ \\
\hline $20 \%$ FA + ethylene glycol & & \\
$0 \cdot 00$ & $1114 \cdot 1$ & $10 \cdot 6058$ \\
$0 \cdot 01$ & $1114 \cdot 5$ & $10 \cdot 7259$ \\
$0 \cdot 05$ & $1118 \cdot 7$ & $11 \cdot 4607$ \\
$0 \cdot 10$ & $1124 \cdot 7$ & $12 \cdot 6732$ \\
$0 \cdot 15$ & $1129 \cdot 6$ & $13 \cdot 7242$ \\
$0 \cdot 20$ & $1134 \cdot 9$ & $14 \cdot 6458$ \\
$40 \%$ FA + ethylene glycol & & \\
$0 \cdot 00$ & & \\
$0 \cdot 01$ & $1116 \cdot 3$ & $7 \cdot 1155$ \\
$0 \cdot 05$ & $1116 \cdot 7$ & $7 \cdot 2113$ \\
$0 \cdot 10$ & $1121 \cdot 4$ & $7 \cdot 6932$ \\
$0 \cdot 15$ & $1126 \cdot 4$ & $8 \cdot 3668$ \\
$0 \cdot 20$ & $1131 \cdot 7$ & $9 \cdot 2680$ \\
$60 \%$ FA + ethylene glycol & $1136 \cdot 9$ & $10 \cdot 0993$ \\
$0 \cdot 00$ & & \\
$0 \cdot 01$ & & \\
$0 \cdot 05$ & $1130 \cdot 9$ & $5 \cdot 1838$ \\
$0 \cdot 10$ & $1121 \cdot 4$ & $5 \cdot 3008$ \\
$0 \cdot 15$ & $1125 \cdot 5$ & $5 \cdot 6865$ \\
$0 \cdot 20$ & $1131 \cdot 5$ & $6 \cdot 3094$ \\
\hline
\end{tabular}

Table 2. Values of partial molar volume $\left(\phi_{v}^{\circ}\right)$ and experimental slope $\left(S_{v}{ }^{*}\right)$ of $\mathrm{MgSO}_{4}$ in FA + ethylene glycol mixtures at infinite dilution, using Masson's empirical equation, at $298 \mathrm{~K}$.

\begin{tabular}{lcc}
\hline $\begin{array}{l}\text { Volume (\%) of FA } \\
\text { in (FA + ethylene glycol) }\end{array}$ & $\phi_{v}{ }^{\circ}\left(10^{-4} \mathrm{~m}^{3} \mathrm{~mol}^{-1}\right)$ & $S_{v} *\left(10^{-4} \mathrm{~m}^{3} \mathrm{dm}^{3 / 2} \mathrm{~mol}^{-3 / 2}\right)$ \\
\hline 20 & 1.8808 & $-1 \cdot 3974$ \\
40 & 1.8349 & -1.4610 \\
60 & 1.7925 & $-1 \cdot 5872$ \\
\hline
\end{tabular}

present study, which are expected to have high dielectric constants since both the liquids FA and ethylene glycol have high dielectric constants 111.0 and $37.7^{11}$, respectively, at 298 K. Negative values of $S_{v} *$ for electrolytes in high dielectric constant media (water and water + formic acid mixtures) have also been reported ${ }^{12}$. This is attributed to the fact that in solvents of high dielectric constant, like FA + ethylene glycol, the salts remain completely ionized, even at fairly high concentrations. As a result, appreciable interionic penetration is likely to occur, giving rise to negative slope for $\phi_{v}$ versus $C^{1 / 2}$ plots ${ }^{1}$.

$\phi_{v}{ }^{\circ}$ is regarded as a measure of ion-solvent interaction. It is evident from table 2 that $\phi_{v}{ }^{\circ}$ values are large positive for $\mathrm{MgSO}_{4}$ in $\mathrm{FA}+$ ethylene glycol mixtures, suggesting the 
presence of strong ion-solvent interactions. Small decrease in $\phi_{v}{ }^{\circ}$ on going from 20 to $60 \% \mathrm{FA}$ indicates the decreasing trend of the ion-solvent interaction as the amount of FA in the solution increases. This, in turn, supports the behaviour of $S_{v}{ }^{*}$ which predicts increased ion-ion interaction as the content of FA in the solution increases. This is contrary to our expectation, as the calculated dielectric constant of FA + ethylene glycol mixtures would increase with increasing amount of FA (with higher dielectric constant) in these mixtures. The dielectric constants of the present mixtures can be calculated using the procedure adopted by Rohdewald and Moldner ${ }^{13}$. These authors calculated the dielectric constants for a binary and ternary or even for higher liquid mixtures using the formula,

$$
\varepsilon_{\text {mix }}=\left[\left(\% \text { solvent }_{1}\right) \varepsilon_{1}+\left(\% \text { solvent }_{2}\right) \varepsilon_{2}+\ldots+\left(\% \text { solvent }_{i}\right) \varepsilon_{i}\right] / 100
$$

The calculated values of dielectric constants for 20, 40 and $60 \%$ FA + ethylene glycol mixtures are found to be 52.36, 67.02 and 81.68 at $298 \mathrm{~K}$. As a result, due to increase in dielectric constant, ion-solvent interaction should increase on going from 20 to $60 \%$ FA in these solutions. However, the observed trend in $\phi_{v}{ }^{\circ}$ (table 2) suggests the reverse. We thus anticipate that solvent-solvent interaction through hydrogen-bonding between FA and ethylene glycol molecules seems to be sufficiently strong to prevent (the expected) increase in ion-solvent interaction as the amount of FA in the solution increases on going from 20 to $60 \%$ FA.

The viscosity data of the present solutions were analysed by using the Jones-Dole ${ }^{5}$ equation,

$$
\eta_{r}=\eta / \eta_{\mathrm{o}}=1+A C^{1 / 2}+B C,
$$

where $\eta$ and $\eta_{\mathrm{o}}$, respectively, are the dynamic viscosities of solution and solvent, $\eta_{r}$ is the relative viscosity of the solution, $A$ is the Falkenhagen coefficient ${ }^{14}$ and is a measure of ion-ion interactions theoretically. On the other hand, $B$, the Jones-Dole coefficient, is empirical and is a function of the ion-solvent interactions. The coefficients $A$ and $B$ were calculated by least-squares fitting of the experimental $\eta$ values in the Jones-Dole equation (4). The values of $A$ and $B$ thus obtained are listed in table 3 . It is observed that the values of $A$-coefficients are very small in all the three solvent mixtures. This indicates the presence of weak ion-ion interactions in the system studied. A perusal of table 3 suggests that the $B$-coefficients for $\mathrm{MgSO}_{4}$ in all the three solvent mixtures are quite positive. This may be attributed to strong ion-solvent interaction in the system.

Furthermore, the viscosity data were also examined in the light of the transition state theory of the relative viscosity of electrolyte solutions proposed by Feakins et $a l^{15}$. According to the theory, $B$-coefficient is given as,

$$
B=\left(\bar{V}_{1}^{0}-\bar{V}_{2}^{0}\right) / 1000+\bar{V}_{1}^{0}\left[\left(\Delta \mu_{2}^{0^{*}}-\Delta \mu_{1}^{0^{*}}\right) / R T\right] / 1000,
$$

where $\bar{V}_{1}^{0}$ and $\bar{V}_{2}^{0}$ are the partial molar volumes of the solvent and solute respectively, $\Delta \mu_{2}^{0^{*}}$ is the contribution per mole of solute to the free energy of activation of viscous flow of the solution and $\Delta \mu_{1}^{0^{*}}$ is the free energy of activation per mole of the pure solvent. The values of $\Delta \mu_{1}^{0^{*} 16}$ and thereafter those of $\Delta \mu_{2}^{0^{*}}$ were calculated using the following equations. 
Table 3. Values of $A$ - and $B$-coefficients of Jones-Dole equation for $\mathrm{MgSO}_{4}$ in FA + ethylene glycol mixtures at $298 \mathrm{~K}$.

\begin{tabular}{lcc}
\hline Volume $(\%)$ of FA in (FA + ethylene glycol) & $A\left(\mathrm{dm}^{3 / 2} \mathrm{~mol}^{-1 / 2}\right)$ & $B\left(\mathrm{dm}^{3} \mathrm{~mol}^{-1}\right)$ \\
\hline 20 & $-0 \cdot 1076$ & $2 \cdot 1970$ \\
40 & -0.1305 & $2 \cdot 3229$ \\
60 & -0.1366 & $2 \cdot 8616$ \\
\hline
\end{tabular}

Table 4. Values of free energy of activation for the solvent $\left(\Delta \mu_{1}^{0^{*}}\right)$ and solute $\left(\Delta \mu_{2}^{0^{*}}\right)$ in FA + ethylene mixtures at $298 \mathrm{~K}$.

\begin{tabular}{lcc}
\hline Volume (\%) of FA in (FA + ethylene glycol) & $\Delta \mu_{1}^{0^{*}}\left(\mathrm{~kJ} \mathrm{~mol}^{-1}\right)$ & $\Delta \mu_{2}^{0^{*}}\left(\mathrm{~kJ} \mathrm{~mol}^{-1}\right)$ \\
\hline 20 & 17.95 & 118.98 \\
40 & $16 \cdot 81$ & $140 \cdot 01$ \\
60 & $15 \cdot 86$ & $176 \cdot 55$ \\
\hline
\end{tabular}

$$
\Delta \mu_{1}^{0^{*}}=R T \ln \left(\eta_{\mathrm{o}} \bar{V}^{0} / h N\right)
$$

and

$$
\Delta \mu_{2}^{0^{*}}=\Delta \mu_{1}^{0^{*}}+\left(R T / \bar{V}^{0}\right)\left[1000 B-\left(\bar{V}_{1}^{0}-\bar{V}_{2}^{0}\right)\right]
$$

where $R, h$ and $N$ are gas constant, Planck's constant and Avogadro's constant respectively, and $T$ is the absolute temperature. The calculated values of $\Delta \mu_{1}^{0^{*}}$ and $\Delta \mu_{2}^{0^{*}}$ are given in table 4 . It is clear form table 4 that $\Delta \mu_{2}^{0^{*}}$ values are very large as compared to those of $\Delta \mu_{1}^{0^{*}}$ in all the three electrolyte + solvent mixtures. Moreover, $\Delta \mu_{2}^{0^{*}}$ tends to increase with increasing amount of FA in the solution. This suggests that the process of viscous flow becomes difficult as the content of FA in the solution increases. This may be attributed to the strong ion-solvent interaction in the solution. Thus, the behaviour of $\Delta \mu_{2}^{0^{*}}$ reinforces our earlier contention that strong ion-solvent interaction exists in the present $\mathrm{MgSO}_{4}+$ mixed solvent systems. It may be noted that for all the $\mathrm{MgSO}_{4}+$ mixed solvent systems $\left(\Delta \mu_{2}^{0^{*}}-\Delta \mu_{1}^{0^{*}}\right)>0$. This is due to the fact that $\mathrm{MgSO}_{4}$ in $\mathrm{FA}+$ ethylene glycol mixed solvent behaves as structure-maker. In fact, Feakins et al ${ }^{15}$ have shown that $\Delta \mu_{2}^{0^{*}}>\Delta \mu_{1}^{0^{*}}$ for electrolytes that are structure-makers. A similar conclusion regarding $\mathrm{MgSO}_{4}$ in dioxane + water mixed solvents were also arrived at by Kannappan and Rajendran ${ }^{17}$ from ultrasonic studies of the above solutions.

\section{Acknowledgements}

The authors (AA, AKN and NK) thank the Department of Science and Technology, Council of Scientific Industrial Research and University Grants Commission, New Delhi for financial support for the project, and Research Associateship and Teacher Fellowship respectively. 


\section{References}

1. Parmar M L and Rao Ch V N 1990 Indian J. Chem. A29 958

2. Osinska S T 1993 Chem. Soc. Rev. 22205

3. Ali A and Nain A K 1994 J. Chem. Res. (S) 80

4. Krestov G A 1991 Thermodynamics of solvation (Chichester: Ellis-Horwood) p. 152

5. Jones G and Dole M 1929 J. Am. Chem. Soc. 512950

6. Ali A and Nain A K 2001 Indian J. Pure Appl. Phys. 39421

7. Vogel A I 1989 Textbook of practical organic chemistry 5th edn (London: Longman)

8. Stokes R H and Mills R 1965 Viscosity of electrolytes and related properties (New York: Pergamon)

9. Masson D O 1929 Philos. Mag. 8218

10. Subha M C S, Rao K C and Rao S B 1986 Indian J. Chem. A25 424

11. Marcus Y 1977 Introduction to liquid state chemistry (New York: Wiley-Interscience) p. 110

12. Chowdoji R K and Brahmaji R S 1983 J. Indian Inst. Sci. B64 41

13. Rohdewald P and Moldner M 1973 J. Phys. Chem. 77373

14. Falkenhagen H and Dole M 1929 Phys. Z. 30 611; Falkenhagen H and Vernon E L 1932 Phys. Z. 33140

15. Feakins D, Freemantle D J and Lawrence K G 1974 J. Chem. Soc., Faraday Trans. I 70795

16. Glasstone S, Laidler K and Eyring H 1941 The theory of rate processes (New York: McGraw Hill)

17. Kannappan A N and Rajendran V 1992 Indian J. Phys. B66 135 